\title{
Assessment of significant coronary artery stenosis using blood oxygen level dependent cardiovascular magnetic resonance (BOLD-CMR)
}

\author{
Jodi Harker ${ }^{1 *}$, Judy Luu', James Hare², Dominik P Guensch, Matthias G Friedrich \\ From 15th Annual SCMR Scientific Sessions \\ Orlando, FL, USA. 2-5 February 2012
}

\section{Summary}

Oxygenation-sensitive CMR at $1.5 \mathrm{~T}$ can be used to identify functionally significant coronary artery stenosis, by demonstrating a blunted response to adenosine induced hyperaemia. Image quality remains a limitation.

\section{Background}

Using the magnetic properties of hemoglobin, changes in myocardial tissue oxygenation can be detected with blood oxygen level dependent (BOLD) cardiovascular MRI (CMR). The study aim was to assess whether BOLD-CMR images can detect an abnormal myocardial tissue response to adenosine infusion in patients with CAD, when compared to fractional flow reserve (FFR).

\section{Methods}

Patients undergoing clinically indicated coronary angiography underwent BOLD CMR scans using a clinical 1.5T scanner. Three short axis BOLD cine images were captured at baseline and during adenosine-induced coronary hyperemia. The mean segmental percent signal intensity (SI) changes were calculated between baseline and hyperemia in the subendocardial myocardium using the 16-segment model. Segments were defined as ischemic or non-ischemic by FFR (cut-off $<0.80$ ). The segment with the lowest BOLD SI percent change per patient was used for analysis.

\section{Results}

Thirty-two patients were enrolled, 5 patients were excluded due to incomplete CMR, leaving 27 patients (age $61 \pm 10$ years) for analysis. There were 864

${ }^{1}$ Stephenson CMR Centre, Libin Cardiovascular Institute, University of Calgary, Calgary, AB, Canada

Full list of author information is available at the end of the article myocardial segments (baseline and adenosine) available for analysis, 289 were subtended by a coronary artery with an available FFR value. Eighty-two segments (28\%) were excluded due to pre-defined criteria for poor image quality, $67 \%$ were apical. From the remaining 20 patients, 7 had ischemic FFR values and 13 had non ischemic FFR values. Using the segment with the lowest $\%$ BOLD SI change per patient there was a significant difference between ischemic $-6.49 \% \pm-8.65 \%$ and non ischemic $4.21 \pm 4.94 \%(\mathrm{p}=0.0023)$ patients. Using a cut off value of $1.1 \%$ SI change the sensitivity is $86 \%$, specificity $69 \%$, positive predictive value 0.6 and negative predictive value 0.9 .

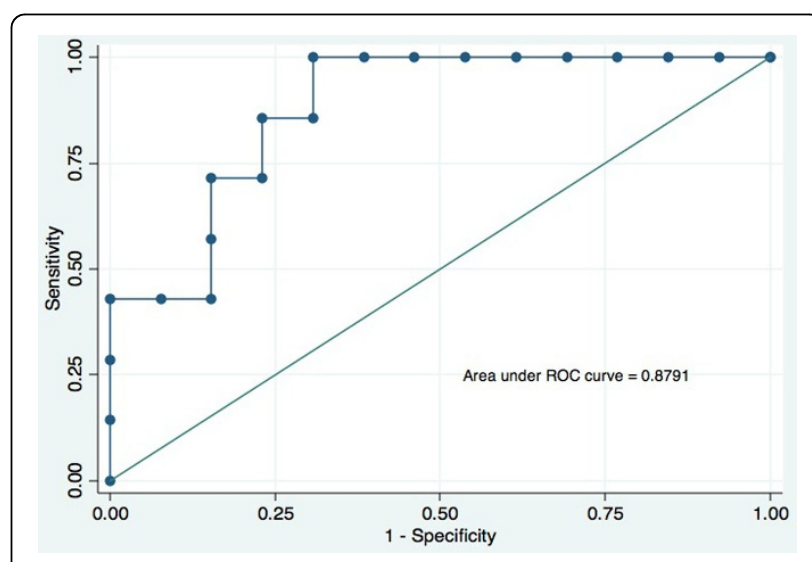

Figure 1 Receiver operating characteristic (ROC) curve for BOLD \% SI change.

(c) 2012 Harker et al; licensee BioMed Central Ltd. This is an open access article distributed under the terms of the Creative Commons 


\section{Conclusions}

A blunted hyperemic response to adenosine as assessed by oxygenation-sensitive CMR at $1.5 \mathrm{~T}$ can identify functionally significant coronary artery stenosis. However, image quality, mainly in apical segments, remains a limitation.

\section{Funding}

Canadian Institute of Health Research.

\section{Author details}

'Stephenson CMR Centre, Libin Cardiovascular Institute, University of Calgary, Calgary, AB, Canada. ${ }^{2}$ Baker IDI Heart \& Diabetes Institute, Melbourne, VIC, Australia

Published: 1 February 2012

doi:10.1186/1532-429X-14-S1-P4

Cite this article as: Harker et al:: Assessment of significant coronary artery stenosis using blood oxygen level dependent cardiovascular magnetic resonance (BOLD-CMR). Journal of Cardiovascular Magnetic Resonance 2012 14(Suppl 1):P4.

Submit your next manuscript to BioMed Central and take full advantage of:

- Convenient online submission

- Thorough peer review

- No space constraints or color figure charges

- Immediate publication on acceptance

- Inclusion in PubMed, CAS, Scopus and Google Scholar

- Research which is freely available for redistribution

Submit your manuscript at www.biomedcentral.com/submit 